\title{
Risk Perception and Personality Facets
}

\author{
Bruno Chauvin, ${ }^{1}$ Danièle Hermand, ${ }^{2}$ and Etienne Mullet $^{3 *}$
}

\begin{abstract}
The present study examined the relationship between personality facets and risk perception using the Big Five model. A broad range of hazards was considered: energy production, pollutants, sex, deviance, addictions, weapons, common individual hazards, outdoor activities, medical care, and psychotropic drugs. Key personality facets that were most predictive of risk perception compared to (or in association with) age, gender, educational level, and personality factors were identified. They were moderation and tranquility (associated with energy production or pollutants), rationality and efficiency (associated with pollutants, sex, deviance, addictions, or weapons), creativity, imagination, and reflection (associated with energy production, pollutants, or common individual hazards), self-disclosure (associated with outdoor activities), and nurturance and tenderness (associated with sex, deviance, addictions, or medical care). These facets may be recommended for use in future studies on risk perception.
\end{abstract}

KEY WORDS: France; personality facets; risk perception

\section{INTRODUCTION}

Risk perception studies conducted on laypeople samples have been aimed at answering two main questions. The first question is: "Why are some hazards considered as riskier than others in the general population?" The second question is: "Why do some individuals perceive some hazards as riskier than other individuals?" While answering the first question has proved to be relatively easy, finding satisfying answers to the second question has been, by contrast, more challenging.

The research strategy followed by researchers attempting to answer the first question was straightforward. They created a set of dimensions likely to characterize different hazards (e.g., voluntary exposure) and correlated judgments (obtained as a function of these characteristics across a variety of

\footnotetext{
1 University of Nantes, France.

2 Charles-de-Gaulle University, France.

3 Institute for Advanced Studies (EPHE), France.

* Address correspondence to Etienne Mullet, Quefes 17 bis, F-31830 Plaisance du Touch, France; tel: +33 561075301 ; etienne.mullet@wanadoo.fr.
}

hazards and global risk assessments) for these same hazards. The psychometric paradigm (Slovic, 1987) remains the best-known illustration of this research strategy. Researchers working in this paradigm have repeatedly shown that (1) the many dimensions characterizing hazards can be grouped into a limited number of factors, and (2) a substantial part of the variance of risk assessments can be explained by a combination of these factors. For example, in the study by Mullet et al. (1993), four factors were identified: the "dread" factor grouped characteristics such as certainly fatal and catastrophic, the "knowledge of the risk" factor grouped characteristics such as known, new, and voluntary, the "evaluative factor" grouped characteristics such as beneficial to society and economically justified, and finally, the "number of people affected" factor grouped characteristics such as number of people exposed. When considered together, the dread factor and the evaluative factor explained no less than $77 \%$ of the variance of the overall risk assessments (see Boholm, 1998, for a review).

The research strategy followed by researchers attempting to answer the second question was much less straightforward. Indeed, characterizing individuals is 
much more complex than characterizing hazards, especially since individual variability is considerable. Consequently, the personal dimensions considered varied widely from one study to the other, mainly as a function of the authors' preferences and choices. Typically, the part of the variance in risk assessment explained by personal factors has proven to be low (Sjöberg, 2003). Many personal dimensions have been considered, including the following: age (e.g., Hermand et al., 1999), gender (e.g., Gustafson, 1998; Sjöberg, 2000), educational level (e.g., Sjöberg, 2000), training in science (e.g., Karpowicz-Lazreg \& Mullet, 1993), income (e.g., Flynn et al., 1994; Palmer, 2003), religious orientation (e.g., Sjöberg \& af Wahlberg, 2002), political preferences (e.g., Sjöberg, 2000), culture (e.g., Mullet et al., 2005), risk attitude (e.g., Vollrath et al., 1999; Sjöberg, 2003), personal experience with the hazard (e.g., Barnett \& Breakwell, 2001; Rogers, 1997), values (e.g., Sjö berg, 2000), social trust (e.g., Vicklund, 2003; Siegrist et al., 2000), anxiety (e.g., Bouyer et al., 2001; Källmén, 2000), self-efficacy (e.g., Kouabenan, 1998; Källmén, 2000), locus of control (e.g., Källmén, 2000), worldviews (e.g., Bouyer et al., 2001; Brenot et al., 1998), new age beliefs (e.g., Sjöberg \& af Wahlberg, 2002), environmental beliefs (e.g., Sjöberg, 2003), the viewpoint (risk for self or risk for others) taken by the person (Hermand et al., 2003; Sjöberg, 2000), and finally the classical personality factors (e.g., Sjöberg, 2003).

Two recent studies by Sjöberg and af Wahlberg (2002) and Sjöberg (2003) well illustrate this approach. Sjöberg and af Wahlberg (2002) correlated general risk assessment regarding a local depository of nuclear waste and three personality factors (Eysenk et al., 1985). The authors found a correlation of 0.23 with neuroticism; in other words, the more neurotic a person declared himself/herself, the more he/she perceived the depository as risky in general. Sjöberg (2003) correlated personal risk assessment regarding unsuitable dietary habits and five personality factors (extracted from a Swedish version of the Myers-Briggs Type Indicator-Mardberg et al., 1994). The results indicated a correlation of -0.23 with conscientiousness; in other words, the more conscientious a person declared himself/herself, the less this person perceived unsuitable dietary habits as risky for himself/herself. In both cases, the part of variance explained was much lower than what is currently found in studies attempting to explain why some hazards are considered as riskier than others in the general population.

\subsection{A Comprehensive Risk Perception Typology}

The present study systematically examined the relationship between personality variables and risk perception by conjoining two broad frameworks: (1) a comprehensive risk perception typology proposed by Bouyer et al. (2001; see also Hermand et al., 2003), and (2) a comprehensive set of personality items proposed by Goldberg (1999).

By factor analyzing risk perception ratings given to 141 different hazards, Bouyer et al. (2001) were able to identify a parsimonious factor structure. Derived from this structure, eight types of hazards were considered in the present study: energy production (e.g., hydroelectric power plant), pollutants (e.g., chemical plants), sex, deviance, and addictions (e.g., marijuana), weapons (e.g., nuclear weapons), common individual hazards (e.g., hair dying), outdoor activities (e.g., swimming pools), medical care (e.g., open heart surgery), and psychotropic drugs (e.g., sleeping pills). These factors were shown to be stable across different cultures (Macri \& Mullet, 2003).

Some of these factors were reminiscent of factors already found in the psychometric paradigm literature (Slovic et al., 1979, 1980, 1985). In these studies, a dread factor was identified. This factor presented two poles: a "dread pole" corresponding to hazards that evoke a gut reaction of dread, and a "common pole" corresponding to hazards that do not evoke a feeling of dread. The pollutants and weapons factors could be considered as close to the "dread" pole of this factor. The common individual hazards factor could be considered as close to "common" pole of this factor. Nevertheless, this eight-factor structure was notably different from the three-factor structure identified in Slovic et al. (1985) and from the four-factor structure identified in Mullet et al. (1993). In Bouyer et al.'s (2001) study, risk perception appeared clearly organized as a function of the kind of hazard: pollutants, medical care, home risks, transportation, and energy production.

The reason for these differences has to be found in the analyzed database. As stated above, in the framework of the classical psychometric paradigm, (1) participants are asked to rate a number of hazards as a function of their aspects: catastrophic, new, voluntary, or known to science, (2) data are aggregated across participants, and (3) the database analyzed is an Aspect $\times$ Hazard matrix. In Bouyer et al. (2001) by contrast, (1) participants were asked to rate a number of hazards as a function of their overall severity, 
(2) data were not aggregated across participants, and

(c) the database analyzed was a Hazard $\times$ Participants data matrix. As a result, the two types of structures correspond to complementary viewpoints as regards to risk perception. While Slovic et al.'s (1985) three-factor structure reflects the way the various aspects structured themselves as a function of the hazards considered (and from the viewpoint of the $a v$ erage participant), Bouyer et al.'s (2001) more complex structure reflects the way the various hazards structured themselves as a function of their perceived severity (and from the viewpoint of the individual participant's perception).

\subsection{A Comprehensive Personality Model}

The past four decades have seen the emergence of an impressive body of research that seems to indicate the presence of five large factors of personality (Digman \& Tackemoto-Chock, 1981; Goldberg, 1981, 1990; Digman, 1990, 1996; Costa \& McCrae, 1992; Howard \& Howard, 1995; Saucier \& Goldberg, 1996, 2002; Saucier \& Ostendorf, 1999) that appear to be "the natural language of the personality" (Goldberg, 1999). These studies investigated various comprehensive sets of trait terms. Trait ratings were analyzed using a wide variety of factor-analytic techniques. These analyses elicited a Big Five factor structure that was evidenced in different data sets (e.g., from different cultures) (Saucier \& Goldberg, 1996; Saucier \& Ostendorf, 1999) as well as with different methods (e.g., self-rating vs. peer-rating) and instruments (e.g., adjective list or description of behaviors) (Goldberg, 1999). Each factor can be considered as the aggregation of numerous categories of items corresponding to narrower aspects of personality that are called facets of personality.

The first factor is extraversion. This factor mainly indicates where most of the energy is directed: in the inner world of thoughts and ideas or in the outer world of events and actions. In the comprehensive set of personality items used to assess a variety of personality models that was offered by Goldberg (1999) - the International Personality Item Pool (IPIP) - the following facets for this factor were proposed: gregariousness, friendliness, assertiveness, poise, leadership, provocativeness, self-disclosure, talkativeness, and sociability (see also Hofstee et al., 1992). The essence of extraversion seems to be naturally related to the idea of being at ease in most personal and social circumstances, even borderline circumstances. Several facets of this factor are even clearly indicative of proneness to deviance or at least a tendency to originality (e.g., provocativeness, self-disclosure, talkativeness). As shown by Vollrath and Torgensen (2002), individuals scoring high on extraversion were particularly inclined to engage in multiple, risky health behaviors. Thus, it could be expected that extroverts should possibly view deviant personal or social behaviors in a more lenient way than introverts do. Indeed, extroverts, by definition, spend less time "reflecting" than "doing." Worrying about risky behaviors may not only take time away from their action-oriented lifestyle, but it could also possibly limit its range.

The second factor is agreeableness. This is a factor clearly related to the way that each individual behaves with others. In the IPIP, Goldberg (1999) has proposed the following nine facets for this factor: understanding, warmth, morality, pleasantness, empathy, cooperation, sympathy, tenderness, and nurturance (see also Hofstee et al., 1992). The essence of this factor seems to be naturally related to the concepts of nonviolence, and care for others and the environment. Thus, it could be expected that more agreeable individuals should possibly consider pollution, violence, and illnesses as more undesirable and hence more risky than the less agreeable individuals. This would mainly be due to their greater ability to empathize with people who are often involuntarily affected by these threats. The essence of this factor also seems to be related to the concept of decent, proper conduct under various circumstances (e.g., the morality facet). Thus, it could be expected that more agreeable individuals should tend to perceive unprotected sex, deviance, and addictions as more risky than less agreeable individuals. As shown by Vollrath et al. (1999), more agreeable individuals tend to engage less often than others in risky health behaviors.

The third factor is conscientiousness. This factor relates to the organized, controlled, determined, and effective manner with which the individual thinks and acts in his/her environment. In the IPIP, Goldberg (1999) has proposed the following facets for this factor: conscientiousness, efficiency, dutifulness, purposefulness, organization, cautiousness, rationality, perfectionism, and orderliness (see also Hofstee et al., 1992). The essence of this factor seems to be naturally related to the concepts of precaution and foresight, and the meaning of most facets of this factor (e.g., cautiousness, orderliness, dutifulness) seems clearly at odds with the idea of deviance. Moreover, as already shown by Lemos Giráldez and Fidalgo Aliste (1997), Vollrath et al. (1999), and Paunonen and Ashton(2001), more conscientious individuals tend to 
engage, less than other people, in risky health behavior such as unprotected sex, smoking, and drinking (see also Hampson et al., 2000). As a result, it may be expected that individuals who score higher on conscientiousness would be more likely to perceive the hazard factor of sex, deviance, and addictions as riskier than people who score lower on conscientiousness.

The fourth factor is emotional stability. This is a factor related to a set of avoidance, withdrawal, and flight behaviors (Davidson, 1998). In the IPIP, Goldberg (1999) has proposed the following nine facets for this factor: stability, happiness, calmness, moderation, toughness, impulse control, imperturbability, cool-headedness, and tranquility (see also Hofstee et al., 1992). The essence of this factor seems to be naturally related to the idea of fearlessness in many circumstances. Thus, a negative relationship may be expected between emotional stability and all hazard factors. This relationship should, however, be stronger for hazard factors such as energy production, pollutants, weapons, and medical care (the factors that tend to trigger dread reactions among the less emotionally stable and the more fearful individuals). Sjöberg (2003), using a shorter Big Five questionnaire and a shorter list of hazards, has previously evidenced a consistent pattern of negative correlations between emotional stability and a set of hazards including AIDS, greenhouse effect, X-ray diagnostics, unsuitable dietary habits, traffic accidents, nuclear waste, sunrays, nuclear arms, violence, and aggression; that is, hazards relative to energy production, pollutants, weapons, and medical care. The essence of the emotional stability factor is also clearly related to the concepts of tranquility, moderation, and toughness. As shown by Flynn et al. (1994), white males, compared to nonwhite males, white females, and nonwhite females, perceive hazards linked with industrial development as less risky than others do (see also Palmer, 2003). In other words, well-trained and better-educated individuals, being politically more conservative, having higher household incomes, higher perceived control over risks to their health, and higher trust in government, authority, and industry (experts, engineers) see less risk in the world. These persons are possibly also those who consider themselves more tranquil, more moderate, and tougher (more calm even in tense situations) than others. Thus, it could be expected that the less emotionally stable people (who logically seem to appear as less tranquil, less moderate, or less tough) may have the opposite reaction, and evaluate these hazards as riskier than the more emotionally stable individuals.
The fifth factor is openness (or intellect). This factor is largely related to the way that the individual perceives the world. In the IPIP, Goldberg (1999) has proposed the following facets for this factor: intellect, ingenuity, reflection, competence, quickness, introspection, creativity, imagination, and depth (see also Hofstee et al., 1992). The essence of this factor seems to be naturally related to the concepts of curiosity and intellectuality. As shown by Pilisuk and Acredolo (1988), better-educated people view technological hazards as less risky than others because they tend to better understand the scientific complexities of this type of hazards. Thus, it could be expected that more open individuals should view modern energy production in a different light than other people (e.g., they may be willing to better understand the often complex technology on which various forms of energy production are based). The essence of this factor also seems to be related to the concept of openmindedness and the idea of "live and let live." Thus, it could be expected that more open individuals should consider free sex and consumption of substances as less problematic and less risky than others. As shown by Booth-Kewley and Vickers (1994), more open individuals tend to give more permissive scores to free sex and consumption of substances than less open individuals.

\subsection{Working at the Facet Level}

An important feature of the present study was that the relationship between risk perception and personality was not only assessed at the factor level (as in previous studies) but also at the facet level; that is, at a more fine-grained level. As shown by Paunonen and Ashton (2001), the consideration of personality facets allows the prediction of significantly larger portions of variance than the consideration of personality factors. The personality scale used was made of selected items from the IPIP (Goldberg, 1999). It was composed of 485 personality items grouped into 45 low-level facets of personality (about 10 items in each facet), and these facets were grouped into the classical Big Five factors.

Many of the IPIP facets are reminiscent of personality dimensions that were previously considered in risk perception studies. For example, (1) the items corresponding to the stability facet, a component of the neuroticism/emotional stability factor, are very close to those in the anxiety scales (Spielberger et al., 1970), (2) the items corresponding to the cooperation facet, a component of agreeableness, are close to those in the egalitarian view scale (Wildavsky \& 
Dake, 1990), and finally (3) the items corresponding to the cautiousness facet, a component of conscientiousness, are close to those in the risk attitude scales (Helmreich et al., 1986). We chose the items of the IPIP mainly because of their ability to encompass, and structure in a parsimonious way, a very broad range of personal dimensions, some previously considered in other studies and some completely new.

\subsection{Hypotheses}

The hypotheses were based on theoretical considerations related to the nature of the personality and hazard factors as well as on previous empirical findings. We expected that: (1) higher levels of extraversion should be associated with lower levels of perceived risks for the sex, deviance, and addictions factor, (2) higher levels of agreeableness should be associated with higher levels of perceived risks for the pollutants, weapons, sex, deviance, addictions, and medical care factors, (3) higher levels of conscientiousness should be associated with higher levels of perceived risks for the sex, deviance, and addictions factor, (4) higher levels of emotional stability should be associated with lower levels of perceived risks for the energy production, pollutants, weapons, and medical care factors, (5) higher levels of openness (intellectuality) should be associated with lower levels of perceived risks for the energy production and sex, deviance, and addictions factors, and finally (6) personality facets should explain (significantly) greater parts of variance as compared to the personality factors alone.

This last hypothesis was partly based on findings by Paunonen and Ashton (2001). These authors compared the relative merits of the Big Five personality factors and facets in terms of their ability to predict a set of 40 behavior criteria that possess some social importance. They showed that (1) personality facets can predict the criteria as well as (or better than) the Big Five factors, and, more importantly, (2) a substantial part of the criterion variance predicted by the facet scales was variance not predicted by the factor scales. This finding supports a more detailed approach to personality assessment, one that goes beyond the measurement of the Big Five factors alone.

\section{METHOD}

\subsection{Participants}

The sample was composed of 795 unpaid participants (400 females and 395 males) recruited on a voluntary basis. They were aged 15 to $87: 53$ participants were 15 to 17 years old, 150 were 18 to 24 years old, 128 were 25 to 29 years old, 165 were 30 to 44 years old, 151 were 45 to 54 years old, 82 were 55 to 64 years old, 47 were 65 to 74 years old, and 19 participants were older than 74 . Two hundred eighty participants had not completed secondary education, 307 had completed secondary education, and 208 had some university degree. As compared with the general population in the country, young persons (15-24) were overrepresented (25\% in the sample vs. $17 \%$ in the country), and older adults (50-89) were underrepresented (27\% vs. $40 \%$ ). However, regarding gender, the distribution was similar to the general population (49\% males in the sample vs. $48 \%$ males in the general population).

Participants were contacted during daylight hours in the main streets of Nantes, a town of half-a-million inhabitants located in the west of France. The research team was composed of 20 students trained in the technique of questionnaires and working under the close supervision of one of the authors (BC). The members of the team were instructed to solicit every third passerby until 1,500 individuals were contacted. The individuals approached were told that our research team was conducting a survey on risk perception and were given either some examples of the questions or shown the first page of the questionnaire. The acceptance rate was moderately high; $53 \%$ of the people contacted agreed to participate in the study. The main reason for refusal to participate seemed to be lack of available time (it took approximately 30 minutes to fill out the questionnaire).

\subsection{Material}

The risk perception questionnaire was composed of 24 items taken partly from Slovic et al.'s risk questionnaire (Slovic et al., 1985) and partly from the Bouyer et al.'s questionnaire. These items covered eight of the domains found in Bouyer et al. (2001) and in Hermand et al. (2003): energy production, pollutants, sex, deviance, addictions, weapons, common individual hazards, outdoor activities, medical care, and psychotropic drugs. Responses were given on an 11-point scale labeled from "no risk" to "extremely severe risk." As in Slovic et al. (1985), the marks on the scale ranged from 0 to $100(0,10,20,30$, etc.).

Five different personality questionnaires were used. Each questionnaire corresponded to one of the five factors of personality: extraversion, agreeableness, conscientiousness, emotional stability/neuroticism, and openness/intellect. Each questionnaire was composed of a variable number of 
items (89 to 106, depending on the factor) taken from the IPIP (Goldberg, 1999). These items included Goldberg's (1992) markers variables. Responses were given on a five-point scale. The response options were 1 (very inaccurate), 2 (moderately inaccurate), 3 (neither inaccurate nor accurate), 4 (moderately accurate), and 5 (very accurate). This description referred to the adequacy of the adjective as a descriptor of oneself.

The French version of the items was composed from the English version. In designing the French version, the authors followed the guidelines proposed in the literature on cross-cultural methodology (Brislin, 2000): independent/blind/back translation, educated translation, small-scale pretests. A translation was executed by a bilingual translator, and sent to another bilingual translator for back translation. Cronbach's alphas were computed for each factor and for each facet of the French version. They ranged from 0.73 to 0.85 for the factors and from 0.56 to 0.86 for the facets.

\subsection{Procedure}

Each participant responded individually. After agreeing to participate in the study, the experimenter immediately conducted the survey during at-home sessions or made an appointment to meet later at the participant's home or at another site. In all cases, the participants filed out the questionnaire in a familiar and calm setting.

Participants were placed in five different experimental conditions according to the personality factor that was considered: 124 participants were presented with the extraversion items, 105 participants with the agreeableness items, 185 participants with the conscientiousness items, 200 participants with the emotional stability items, and 181 participants with the openness items. In each of the five conditions, the participants were also presented with the risk perception questionnaire. In each condition, half of the participants were given the risk perception questionnaire first and the personality questionnaire next, and the remaining half were given the personality questionnaire first and the risk perception questionnaire next.

Participants were informed that the term "risk" referred to the risk for the entire population of the world of being seriously ill, wounded, or dying. They were invited to ask questions about unfamiliar terms and then to fill out the questionnaire. When an item did not evoke anything concrete, participants were allowed not to respond. No time limit was imposed.
Responses were recorded in two successive steps. First, participants were invited to circle, with a black pencil, the number between 0 and 100 that best reflected their view. Then, the participants were allowed to change their responses using a red pencil. In addition, they were requested to clearly differentiate risks as much as possible. The main goal of this two-step procedure was to ensure that participants used the entire range of the response scales.

\section{RESULTS}

\subsection{Structure of the Risk Perception Questionnaire}

A confirmatory factor analysis was conducted on the 24 items from the risk perception questionnaire. The model tested was a correlated eight-factor model hypothesized based on studies by Bouyer et al. (2001) and Hermand et al. (2003). This model is shown in Table I. All path coefficients were significant (GFI $\left.=0.93, \mathrm{CFI}=0.94, X^{2} / d f=3.09, \mathrm{RMSEA}=0.05\right)$.

A mean score was computed for each factor by simply averaging the scores of the three corresponding items.

\subsection{Relationships Between Hazard Factors and Demographic Characteristics}

Table II shows the correlation coefficients computed between the eight hazard factors and the participants' gender, age, and educational level. Due to the great number of correlation coefficients computed, the significance threshold was set at 0.01 .

The energy production factor significantly correlated with gender; women perceived energy production as more risky than men. The sex, deviance, and addictions factor significantly correlated with all three demographic characteristics. Women, older participants, and less educated participants perceived sex and addictions as more risky than men, younger participants, and more educated participants, respectively. The weapons factor also significantly correlated with age and educational level. The younger and the more educated the participant, the higher was the perceived risk level. The common and individual hazards factor significantly correlated with age. The older the participant, the higher was the perceived risk level. Finally, the medical care factor also significantly correlated with age. The older the participant, the lower was the perceived risk level. 
Table I. Results from the Confirmatory Factor Analysis Conducted on the Risk Perception Items

\begin{tabular}{|c|c|c|c|c|c|c|c|c|c|c|}
\hline \multirow[b]{2}{*}{ Items } & \multicolumn{7}{|c|}{ Factors } & \multirow[b]{2}{*}{ VIII } & \multirow[b]{2}{*}{$M$} & \multirow[b]{2}{*}{$S D$} \\
\hline & I & II & III & IV & $\mathrm{V}$ & VI & VII & & & \\
\hline Hydroelectric power plants & 0.84 & & & & & & & & 33.03 & 24.06 \\
\hline Solar power plants & 0.71 & & & & & & & & 20.62 & 21.03 \\
\hline Thermal power plants & 0.62 & & & & & & & & 43.67 & 26.08 \\
\hline Chemical fertilizers & & 0.79 & & & & & & & 66.21 & 25.56 \\
\hline Chemical plants & & 0.72 & & & & & & & 68.92 & 23.16 \\
\hline Deforestation & & 0.60 & & & & & & & 71.70 & 25.81 \\
\hline Heterosexual relationships with multiple partners & & & 0.99 & & & & & & 59.48 & 29.10 \\
\hline Homosexual relationships with multiple partners & & & 0.92 & & & & & & 63.47 & 28.88 \\
\hline Marijuana & & & 0.40 & & & & & & 63.13 & 30.93 \\
\hline Bacteriological weapons & & & & 0.81 & & & & & 92.98 & 14.92 \\
\hline Nuclear weapons & & & & 0.79 & & & & & 95.55 & 11.58 \\
\hline Handguns & & & & 0.54 & & & & & 84.25 & 21.65 \\
\hline Hair dying & & & & & 0.69 & & & & 19.70 & 18.77 \\
\hline Computer screens & & & & & 0.66 & & & & 31.30 & 23.94 \\
\hline Food colorants & & & & & 0.64 & & & & 33.06 & 24.72 \\
\hline Bridges & & & & & & 0.76 & & & 19.81 & 16.96 \\
\hline Urban transportation & & & & & & 0.72 & & & 23.77 & 18.15 \\
\hline Swimming pools & & & & & & 0.71 & & & 30.79 & 21.61 \\
\hline Surgery & & & & & & & 0.86 & & 40.10 & 21.45 \\
\hline Open heart surgery & & & & & & & 0.79 & & 58.75 & 25.39 \\
\hline Anesthetics & & & & & & & 0.58 & & 47.04 & 23.21 \\
\hline Sleeping pills & & & & & & & & 0.87 & 48.74 & 24.54 \\
\hline Tranquilizers & & & & & & & & 0.87 & 48.75 & 25.44 \\
\hline Antidepressants & & & & & & & & 0.63 & 52.33 & 23.89 \\
\hline
\end{tabular}

Note: $\mathrm{I}=$ energy production, $\mathrm{II}=$ pollutants, $\mathrm{III}=$ sex, deviance, and addictions, $\mathrm{IV}=$ weapons, $\mathrm{V}=$ common individual hazards, $\mathrm{VI}=$ outdoor activities, VII = medical care, VIII = psychotropic drugs.

\subsection{Relationships Between Hazard Factors and Personality}

For each personality factor, a mean score was computed by averaging the scores of the corresponding items. For these computations, the Fifty Markers scheme (Goldberg, 1992) was chosen (since each factor in this version corresponds to 10 items, which is approximately comparable to the average number of items included in each facet). Alpha values ranged from 0.73 to 0.85 .
For each personality facet, a mean score was also computed by averaging the scores of the corresponding items (ranging from 8 to 13 according to facets). Alpha values ranged from 0.56 to 0.86 . Correlation coefficients were computed between the five personality factors and the eight risk perception scores, and between the 45 personality facets scores and the eight risk perception scores. They are shown in Table III.

A series of stepwise regression analyses were conducted to examine whether the facets explained

Table II. Correlations Between Demographic Characteristics and Hazard Factors $(N=795)$

\begin{tabular}{|c|c|c|c|c|c|c|c|c|}
\hline $\begin{array}{l}\text { Demographic } \\
\text { Characteristics }\end{array}$ & Energy & Pollutants & $\begin{array}{l}\text { Sex and } \\
\text { Addict. }\end{array}$ & Weapons & Common & Outdoor & Care & $\begin{array}{l}\text { Psych. } \\
\text { Drugs }\end{array}$ \\
\hline Gender & $0.32^{* * *}$ & & $0.21^{* *}$ & & & & & \\
\hline Age & & & $0.27^{* * *}$ & $-0.24^{* *}$ & $0.32^{* * *}$ & & $-0.22^{* *}$ & \\
\hline Education & & & $-0.25^{* * *}$ & $0.21^{* *}$ & & & & \\
\hline$R$ & $0.32^{* * *}$ & & $0.37^{* * *}$ & $0.27^{* * *}$ & $0.32^{* * *}$ & & $-0.22^{* *}$ & \\
\hline
\end{tabular}

Note: ${ }^{* *} p<0.01,{ }^{* * *} p<0.001$. Nonsignificant correlations were deleted. 
Table III. Correlations Between Personality Facets, Personality Factors, and Hazard Factors

\begin{tabular}{|c|c|c|c|c|c|c|c|c|}
\hline Facets & Energy & Pollutants & $\begin{array}{l}\text { Sex and } \\
\text { Addict. }\end{array}$ & Weapons & Common & Outdoor & Care & $\begin{array}{l}\text { Psych. } \\
\text { Drugs }\end{array}$ \\
\hline & \multicolumn{8}{|c|}{ Extraversion $(N=124)$} \\
\hline \multicolumn{9}{|l|}{ Gregariousness } \\
\hline \multicolumn{9}{|l|}{ Friendliness } \\
\hline \multicolumn{9}{|l|}{ Assertiveness } \\
\hline \multicolumn{9}{|l|}{ Poise } \\
\hline Leadership & & & $-0.21^{* *}$ & & & & & \\
\hline Provocativeness & & & $-0.23^{* *}$ & & $-0.22^{* *}$ & & & \\
\hline Self-disclosure & & & $-0.27^{* * *}$ & & $-0.32^{* * *}$ & $-0.21^{* *}$ & & \\
\hline Talkativeness & & & $-0.24^{* *}$ & & $-0.21^{* *}$ & & & \\
\hline \multicolumn{9}{|l|}{ Sociability } \\
\hline \multirow{2}{*}{\multicolumn{9}{|c|}{$\begin{array}{l}\text { Factor } \\
R^{2} \text { change }\end{array}$}} \\
\hline & & & & & & & & \\
\hline & \multicolumn{8}{|c|}{ Agreeableness $(N=105)$} \\
\hline Understanding & & & $0.23^{* *}$ & & & & $0.22^{* *}$ & \\
\hline Warmth & $0.22^{* *}$ & & $0.30^{* * *}$ & & & & & \\
\hline Morality & & & $0.31^{* * *}$ & & & & & \\
\hline Pleasantness & & & $0.26^{* * *}$ & & & & & \\
\hline Empathy & & $0.20^{* *}$ & $0.20^{* *}$ & & & & $0.22^{* *}$ & \\
\hline Cooperation & & & & & & & & $0.20^{* *}$ \\
\hline Sympathy & & & & & & & & \\
\hline Tenderness & $0.36^{* * *}$ & & $0.25^{* * *}$ & $0.20^{* *}$ & & $0.30^{* * *}$ & $0.35^{* * *}$ & \\
\hline Nurturance & $0.29^{* * *}$ & $0.21^{* *}$ & $0.31^{* * *}$ & & $0.25^{* * *}$ & $0.21^{* *}$ & & \\
\hline Factor & & & $0.28^{* *}$ & & & & $0.21^{* *}$ & \\
\hline \multirow[t]{2}{*}{$R^{2}$ change } & & & 0.05 & & & & $0.08^{* *}$ & \\
\hline & \multicolumn{8}{|c|}{ Conscientiousness $(N=185)$} \\
\hline Conscientiousness & & & $0.33^{* * *}$ & & & & & \\
\hline Efficiency & & & $0.39^{* * *}$ & & $0.20^{* *}$ & & & \\
\hline Dutifulness & & & $0.30^{* * *}$ & & & & & \\
\hline Purposefulness & & & $0.34^{* * *}$ & & & & & \\
\hline Organization & & & $0.31^{* * *}$ & & & & & \\
\hline Cautiousness & & $-0.24^{* *}$ & $0.25^{* * *}$ & $-0.21^{* *}$ & & & & \\
\hline Rationality & & $-0.28^{* * *}$ & $0.25^{* * *}$ & $-0.28^{* * *}$ & & & & \\
\hline Perfectionism & & & $0.24^{* *}$ & $-0.23^{* *}$ & & & & \\
\hline Orderliness & & $-0.20^{* *}$ & $0.30^{* * *}$ & $-0.27^{* *}$ & & & & \\
\hline Factor & & & $0.34^{* * *}$ & $-0.20^{* *}$ & & & & \\
\hline \multirow[t]{2}{*}{$R^{2}$ change } & & & $0.04^{* *}$ & $0.04^{* *}$ & & & & \\
\hline & \multicolumn{8}{|c|}{ Emotional stability $(N=200)$} \\
\hline Stability & $-0.22^{* *}$ & & & & & & & \\
\hline Happiness & $-0.24^{* *}$ & & & & & & & \\
\hline Calmness & $-0.21^{* *}$ & & & & & & & \\
\hline Moderation & $-0.21^{* *}$ & & & & & & $-0.21^{* *}$ & \\
\hline Toughness & $-0.26^{* * *}$ & & & & & & & \\
\hline Impulse control & $-0.21^{* *}$ & & & & & & & \\
\hline Imperturbability & $-0.25^{* * *}$ & $-0.22^{* *}$ & & & & $-0.21^{* *}$ & & \\
\hline Cool-headedness & & & & & & & & \\
\hline Tranquility & $-0.23^{* *}$ & $-0.24^{* *}$ & & & & & & \\
\hline Factor & $-0.22^{* *}$ & & & & & & & \\
\hline$R^{2}$ change & 0.02 & & & & & & & \\
\hline
\end{tabular}


Table III. (Continued)

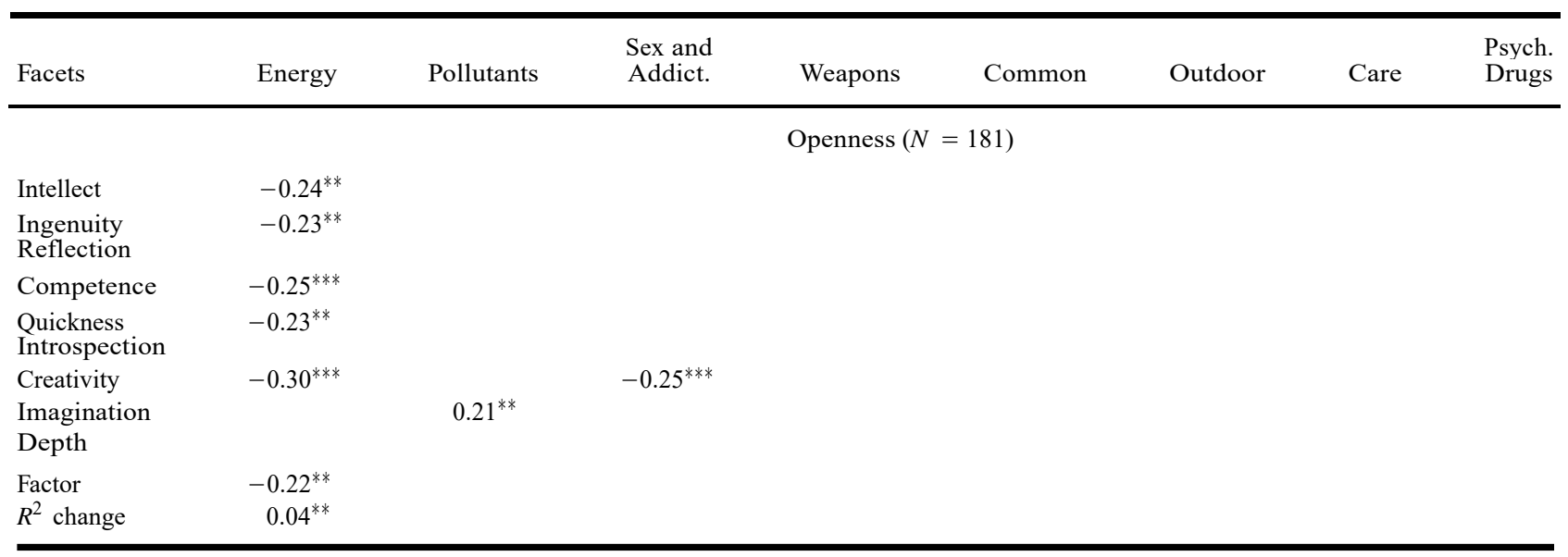

Note: Part of additional variance $\left(R^{2}\right)$ explained by the facet with the highest correlation over the corresponding factor.

${ }^{* *} p<0.01,{ }^{* * *} p<0.001$. Nonsignificant correlations were deleted.

a significantly greater part of the variance as compared to the corresponding personality factors. In these analyses, a hazard factor was selected as the criterion, the personality factor was entered at step 1 , and the facet with the highest correlation was entered at step 2 . The $R^{2}$ change was evaluated to see if the facet predicted variance over and above that explained by the factor (there were no cases where a second facet entered at step 3 added a significant part of variance over the factor entered at step 1 and the facet entered at step 2). Results are also shown in Table III.

The energy production factor significantly correlated with the emotional stability and openness factors as well as with eight (out of nine) emotional stability facets, five openness facets, and three agreeableness facets. The more emotionally stable the participants, or the more creative, competent, intellectual, ingenious, and quick the participants, the lower was their perceived risk of energy production. In contrast, the more nurturing, tender, and warm the participants, the higher was their perceived risk of energy production. The toughness facet did not add a significant part of variance over the variance explained by the emotional stability factor. The creativity facet added a significant part of variance over the variance explained by the openness factor.

The pollutants factor significantly correlated with two emotional stability facets, three conscientiousness facets, one openness facet, and two agreeableness facets. The more tranquil and imperturbable the participants, or the more rational, cautious, and orderly the participants, the lower was their perceived risk of pollutant activities. In contrast, the more imaginative or the more nurturing and empathetic the participants, the higher was their perceived risk of pollutant activities.

The sex, deviance, and addictions factor significantly correlated with the conscientiousness and agreeableness factors as well as with all of the conscientiousness facets, one facet of the openness factor, four facets of the extraversion factor, and seven facets of the agreeableness factor. The more conscientious the participants or the more agreeable the participants, the higher was their perceived risk of sex and addictions. In contrast, the more creative the participants, or the more self-disclosing, talkative, provocative, and leader-minded the participants, the lower was their perceived risk of sex and addictions. The efficiency facet added a significant part of variance over the variance explained by the conscientiousness factor. However, the nurturance facet did not add a significant part of variance over the variance explained by the agreeableness factor.

The weapons factor significantly correlated with the conscientiousness factor as well as with four conscientiousness facets and one agreeableness facet. The more rational, orderly, perfectionist, and cautious the participants, the lower was their perceived risk of weapons. On the contrary, the more tender the participants, the more they considered weapons as risky. The rationality facet added a significant part of variance over the variance explained by the conscientiousness factor. 
The common and individual hazards factor significantly correlated with one conscientiousness facet, three extraversion facets, and one agreeableness facet. The more efficient the participants or the more nurturing the participants, the more they considered the common and individual hazards as risky. In contrast, the more self-disclosing, provocative, and talkative the participants, the lower was their perceived risk of the common and individual hazards.

The outdoor factor was significantly correlated with one facet of the emotional stability factor, one facet of the extraversion factor, and two facets of the agreeableness factor. The more imperturbable, or the more self-disclosing the participants, the less they considered outdoor activities as risky. In contrast, the more tender and nurturing the participants, the higher was their perceived risk of outdoor activities.

The medical care factor was significantly correlated with the agreeableness factor as well as with one emotional stability facet and three agreeableness facets. The more moderate the participants, the less they considered medical care as risky. In contrast, the more tender, understanding, and empathetic the participants, the higher was their perceived risk of medical care. The tenderness facet added a significant part of variance over the variance explained by the agreeableness factor.

The psychotropic drug factor was significantly correlated with only one facet of agreeableness. The more cooperative the participants, the higher was their perceived risk of psychotropic drugs.

\subsection{Comparing Demographic Characteristics and Personality Traits as Predictors of Risk Perception}

A series of stepwise regression analyses were conducted in order to determine the best predictor (or combination of predictors) for each risk factor. In these analyses, the predictors were the demographic characteristics, the personality factors, and the personality facets. Results are shown in Table IV.

Regarding the energy factor, the strongest association in general was with gender (see Table II). However, when the creativity facet was considered in the analysis, it was selected at step 1, and gender was relegated to the second position of importance as predictor. Also, when the moderation facet was considered in the analysis, it added a significant part of variance over gender. Regarding the pollutants factor, age, gender, and education seemed in general not to have any effect. The strongest association observed was always with one or another of the following facets: tranquility, rationality, and imagination.

Regarding the sex, deviance, and addictions factor, there was a strong association in general with age, gender, and education. However, when the efficiency or the nurturance facet was considered in the analysis, each was selected at step 1 and the three demographic variables were selected at step 2 or not at all. In other words, the efficiency or the nurturance facet was each a more important predictor than age, gender, and education. Regarding the weapons factor, the strongest associations in general were with age and educational level. However, when the rationality facet was considered in the analysis it was selected at step 1, and these variables were relegated to lower positions as predictors.

Regarding the common and individual hazards factor, the strongest associations in general were with the age factor. However, when the reflection facet was considered in the analysis, it added a significant part of variance over age. Regarding the outdoor factor, age, gender, and education seemed in general not to have any systematic effect. The self-disclosure facet explained, however, a modest part of variance.

Regarding the medical care factor, the strongest association in general was with age, but when the tenderness facet was considered in the analysis, it was selected at step 1, and age was relegated to a lower position as predictor. Finally, regarding the psychotropic drugs factor, age, gender, and education seemed in general not to have any systematic effect. A significant association with gender was, however, found in three subsamples.

\section{DISCUSSION}

The present study examined the relationship between personality variables and risk perception regarding eight types of hazards: energy production, pollutants, sex, deviance, addictions, weapons, common individual hazards, outdoor activities, medical care, and psychotropic drugs.

The first hypothesis was that higher levels of extraversion should be associated with lower levels of perceived risks on the sex, deviance, and addictions factor. This hypothesis may be considered as partly supported by the data. The highest link was found with self-disclosure. This result was consistent with the findings by Vollrath and Torgersen (2002). Unexpectedly, we also found a negative association between three extraversion facets - self-disclosure, provocativeness, and talkativeness - and common individual 
Table IV. Results of the Stepwise Analyses of Regression with the Hazard Factors as the Criterion, and the Demographic Characteristics, the Personality Factors, and the Personality Facets as the Predictors

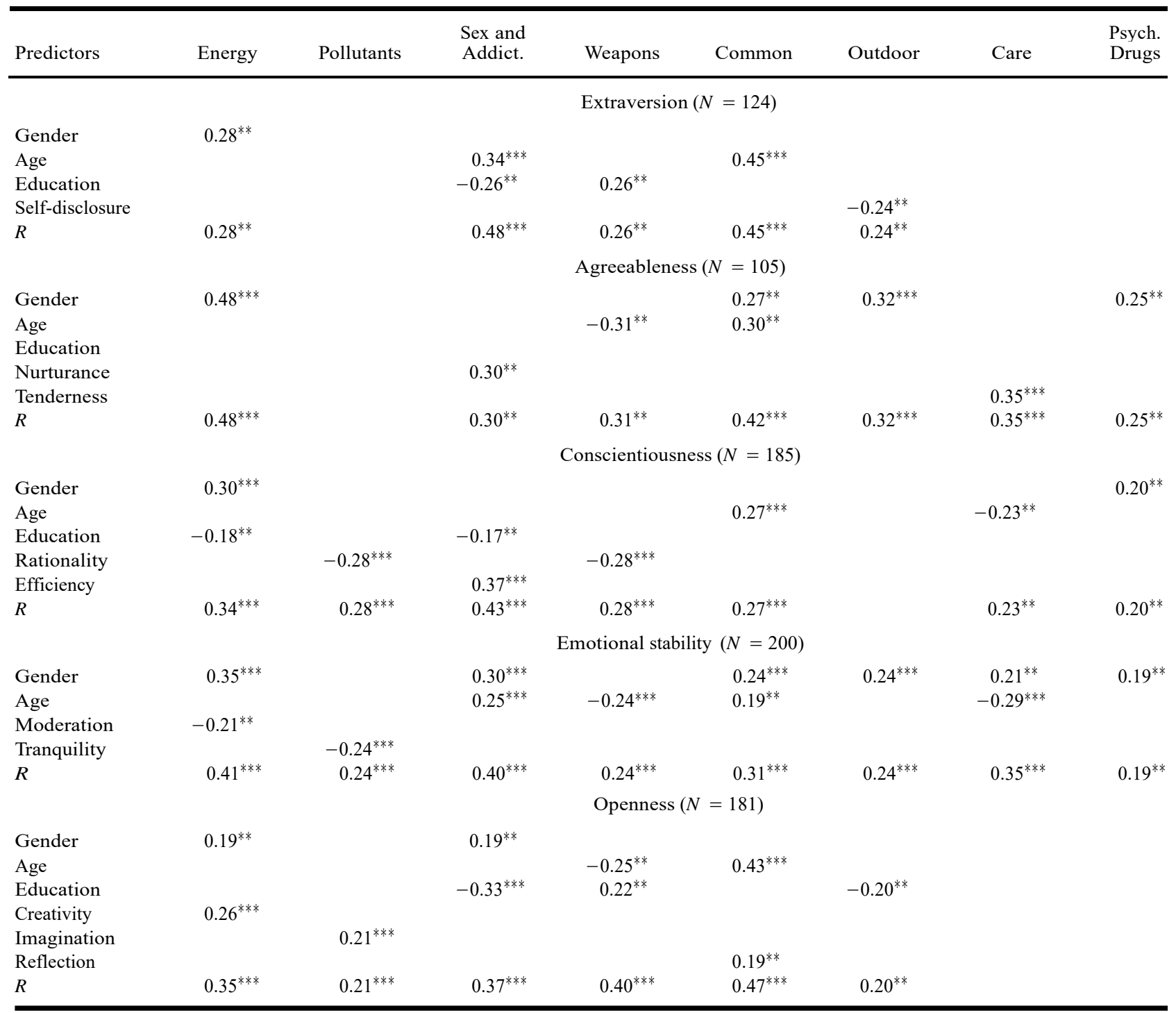

Note: Beta values are reported. Multiple correlations $(R)$ between the criterion and the selected set of predictors.

${ }^{* *} p<0.01,{ }^{* * *} p<0.001$. Nonsignificant values were deleted.

hazards. In other words, individuals with higher scores in these facets tended to be less preoccupied with this type of everyday and a priori insignificant hazard. This may be explained by the fact that the more extroverted individuals tend to be less introspective and more action oriented. In other words, as they live in a world of action, the world of inner thoughts and ideas means less to them than what is "happening" in the outer world. Thus, logically, common individual hazards may be considered as a necessary part of the everyday action-oriented life for which they have a clear preference. In summary, extraversion was found to be negatively associated with hazards associated with individual behaviors.

The second hypothesis was that higher levels of agreeableness should be associated with higher levels of perceived risks on the pollutants, weapons, sex, deviance, addictions, and medical care factors. Regarding pollutants, this hypothesis was partly supported by the data: only two significant associations were 
evidenced. The highest link was found with the nurturance facet. Regarding sex, deviance, and addictions, the hypothesis was supported by the data. The agreeableness factor significantly correlated with sex, deviance, and addictions. At the facet level, the highest link was found, understandably, with morality. This result was consistent with findings by Vollrath et al. (1999). Regarding medical care, this hypothesis was also supported by the data. The agreeableness factor significantly correlated with medical care. At the facet level, the highest link was found with tenderness. Regarding weapons, however, this hypothesis was not supported by the data: only one weak association was found with the tenderness facet. In summary, agreeableness was positively associated, through two or more facets, to five of the eight types of hazards considered (pollutants, sex, deviance, addictions, medical care, energy production, and outdoor activities).

The third hypothesis was that higher levels of conscientiousness should be associated with higher levels of perceived risks on the sex, deviance, and addictions factor. This hypothesis was also supported by the data. The conscientiousness factor significantly correlated with the sex, deviance, and addictions factor. At the facet level, the highest link was found with the efficiency and purposefulness facets. This result was consistent with findings by Lemos Giráldez and Fidalgo Aliste (1997), Vollrath et al. (1999), and Paunonen and Ashton (2001), and with findings by Hampson et al. (2000) showing that conscientiousness was positively linked with positive changes in smoking habits. What was not expected was that several facets of the conscientiousness factor, notably the rationality facet, were negatively linked with the pollutants factor and the weapons factor. More precisely, more rational persons tended to consider the risk associated with pollutants and the risk associated with weapons as weaker than less rational individuals. One way to interpret this result is to speculate that rational individuals may believe that (1) pollution is an unavoidable side effect of development that will be controlled in the medium term, and (2) weapons are only used on a rational basis; that is, as the last resort. Another way to explain this result is to speculate about the relationship between conscientiousness and rules, order, and authority. Individuals with higher scores in conscientiousness tend to follow rules and respect authority. Questioning wars, pollution, etc., comes close to questioning the established order and the higher authorities who make such decisions. Indeed, it takes a less conventional, more rebellious, and more adventurous mind to question such recurrent and ongoing events such as war and pollution. In summary, conscientiousness was found to be positively associated with the hazard factor concerning the general concept of physical health, and negatively associated with the two hazard factors corresponding to the idea of violence to nature (human pollution) and intergroup conflicts.

The fourth hypothesis was that higher levels of emotional stability should be associated with lower levels of perceived risks on the energy production, pollutants, weapons, and medical care factors. Regarding energy production, this hypothesis was supported by the data. Indeed, the emotional stability factor significantly correlated with the energy production factor. At the facet level, the highest link was found with the toughness facet. Regarding pollutants, this hypothesis was supported for the imperturbability and tranquility facets. Regarding weapons and medical care, this hypothesis was not supported by the data. In summary, emotional stability was found to be negatively associated with the two hazard factors that correspond closest to the idea of industrial and economic development. This result was consistent with findings by Sjöberg (2003).

The fifth hypothesis was that higher levels of openness/intellect should be associated with lower levels of perceived risks on the energy production factor. This hypothesis may be considered as mostly supported by the data. The openness factor significantly correlated with the energy production factor. At the facet level, the highest link was found with the creativity facet. This result was consistent with the findings by Pilisuk and Acredolo (1988). The fifth hypothesis also supposed that higher levels of openness/intellect should be associated with lower levels of perceived risks on the sex, deviance, and addictions factor. This was not supported by the data. In fact, only one facet of openness (creativity) was found to be negatively associated with this risk factor. Openness is thus to be clearly distinguished from sexual permissiveness.

Finally, the sixth hypothesis was that personality facets should explain significant additional parts of the variance in comparison to each corresponding personality factor alone. This is what was evidenced in numerous cases. In six cases, a significant association between one hazard factor and one personality factor was evidenced. In four of these six cases, at least one of the corresponding facets added a significant part of variance over the factor. In 16 additional cases, a significant association between at least one facet and one hazard factor was evidenced where no significant association with a personality factor was present (in the remaining 18 cases, there was no significant 
association with any personality trait). Also, when demographic characteristics, personality factors, and personality facets were conjointly entered into the analyses, the personality facets were the strongest predictors of risk perception for six of the eight hazard factors considered in the study (energy production, pollutants, sex, deviance, addictions, weapons, outdoor activities, and medical care). However, for the seventh factor (common and individual hazards), a personality facet added a significant part of variance over a demographic characteristic.

\subsection{Personality Profiles}

The sex, deviance, and addictions factor was shown to present the highest links with personality variables. The variance of this factor was partly explained by the efficiency facet (about 15\% of the variance), the nurturance facet (about 10\% of the variance), the self-disclosure facet (about $8 \%$ of the variance), and finally, the creativity facet (about $6 \%$ of the variance). In this category, the profile of the low risk perceiver is that of a young, more educated, male individual with less efficiency in life, lower nurturance, higher self-disclosure level, and higher creativity; a profile that was already partly suggested by Vollrath et al. (1999).

The energy production factor was shown to present the second highest links with personality variables. This factor's variance was partly explained by the tenderness facet (about 13\% of the variance), the creativity facet (about 9\% of the variance), and the toughness facet (about 7\%). In this category, the profile of the low risk perceiver is that of a male individual with less tenderness toward others, higher creativity level, and higher toughness. This result is consistent with findings by Flynn et al. (1994) and Palmer (2003). According to these authors, white males perceived hazards linked with industrial development as less risky than white females, nonwhite males, and nonwhite females; in other words, individuals with less toughness and more tenderness, and likely to be more concerned about the well-being of others.

Regarding the pollutants factor, the variance was partly explained by the rationality facet (about $8 \%$ ), the tranquility facet (about $6 \%$ ), the imagination facet (about 4\%), and the nurturance facet (about 4\%). In this category, the profile of the low risk perceiver is that of an individual with higher rationality, higher tranquility, lower imagination, and lower nurturance toward others. This is mostly the same profile as that suggested for energy production (see Palmer, 2003).
Regarding the medical care factor, the tenderness facet explained about $12 \%$ of the variance and the moderation facet about $4 \%$. In this category, the profile of the low risk perceiver is that of an older individual with a higher sense of moderation and less tenderness.

In summary, the present study identified the key personality facets (in each factor) that were most predictive of risk perception compared to (or in association with) age, gender, educational level, and personality factors. These facets were moderation and tranquility (associated with energy production or pollutants), rationality and efficiency (associated with pollutants, sex, deviance, addictions, or weapons), creativity, imagination, and reflection (associated with energy production, pollutants, or common individual hazards), self-disclosure (associated with outdoor activities), and nurturance and tenderness (associated with sex, deviance, addictions, or medical care). These facets may be recommended for use in future studies.

\subsection{Limitations}

The main limitation of the study resides in the way that the sample was constituted. Participants were volunteers, and although special efforts were made to recruit people from both genders, different ages, and different educational levels, our sample was not perfectly representative. As a result, the value of the present study is not in precisely estimating the size of the effect of each personality facet on each hazard factor, but in adding evidence in understanding the complex way personality and risk perception are related. It should be noted, however, that a correlation coefficient was computed over the overall means for the 24 hazards included in the present study and the corresponding means reported in the study by Bouyer et al. (2001), and that its value was no less than 0.99 . In other words, between these two imperfectly representative samples (drawn from two different parts of the country), similarities regarding risk perception largely exceeded dissimilarities.

A second limitation in the study is that all the factors, and their corresponding facets, could not be simultaneously entered as predictors since the participants were presented with only one set of personality items corresponding to only one factor (for practical reasons, participants could not be presented with all five sets). As a result, it cannot be stated that the overall part of variance of any hazard factor explained by the facets is the exact sum of the parts of variance explained by each facet taken separately. For instance, 
we cannot state that the overall part of variance for the sex, deviance, and addictions factor explained by the four above-mentioned facets is $39 \%(15 \%+10 \%$ $+8 \%+6 \%)$, mainly because of the possible overlap in variance explained by several facets. Futures studies using the 10 more promising facets are needed for more precisely assessing the exact part of variance explained by each personality facet.

\section{ACKNOWLEDGMENTS}

This work was supported by the SAFE European Network, the MIRE (Convention 2000-2002), the UPRES Education, Cognition, Développement (University of Nantes), the UMR Travail et Cognition (Mirail University), and the MSH Ange Guépin (University of Nantes). Thanks are extended to Sheila Rivière and Félix Neto for their thoughtful comments on an earlier draft of this article.

\section{REFERENCES}

Barnett, J., \& Breakwell, G. M. (2001). Risk perception and experience: Hazard personality profiles and individual differences. Risk Analysis, 21, 171-178.

Boholm, A. (1998). Comparative studies of risk perception: A review of twenty years of research. Journal of Risk Research, 1, $135-163$.

Booth-Kewley, S., \& Vickers, R. R. (1994). Association between major domains of personality and health behavior. Journal of Personality, 62, 281-298.

Bouyer, M., Bagdassarian, S., Chaabane, S., \& Mullet, E. (2001). Personality correlates of risk perception. Risk Analysis, 21, 457-465.

Brenot, J., Bonnefous, N., \& Marris, C. (1998). Testing the cultural theory of risk in France. Risk Analysis, 18, 729-739.

Brislin, R. W. (2000). Some methodological concerns in intercultural and cross-cultural research. In R. W. Brislin (Ed.), Understanding Culture's Influence on Behavior, 2nd ed. Fort Worth: Harcourt.

Costa, P. T., \& McCrae, R. R. (1992). Revised NEO Personality Inventory (NeO-PI-R) and NEO Five-Factor Inventory (NEOFFI): Professional Manual. Odessa, FL: Psychological Assessment Resources.

Davidson, R. J. (1998). Affective style and affective disorders: Perspectives from affective neuroscience. Cognition and Emotion, 12, 307-330.

Digman, J. M. (1990). Personality structure: Emergence of the fivefactor model. Annual Review of Psychology, 41, 417-440.

Digman, J. M. (1996). The curious history of the five-factor model. In J. S. Wiggins (Ed.), The Five-Factor Model of Personality: Theoretical Perspective (pp.1-20). Guilford Press.

Digman, J. M., \& Takemoto-Chock, N. K. (1981). Factors in the natural language of personality: Reanalysis, comparison, and interpretation of six major studies. Multivariate Behavioral Research, 16, 149-160.

Eysenck, S. B. G., Eysenck, H. J., \& Barett, P. (1985). A revised version of the psychoticism scale. Personality and Individual Differences, 6, 21-29.
Flynn, J., Slovic, P., \& Mertz, C. K. (1994). Gender, race, and perception of environmental health risks. Risk Analysis, 14, 11011108.

Goldberg, L. R. (1981). Language and individual differences: The search for universals in personality lexicons. In L. Wheeler (Ed.), Review of Personality and Social Psychology (Vol. 2, pp. 141-165). Beverly Hills, CA: Sage.

Goldberg, L. R. (1990). An alternative "description of personality": The big-five factor structure. Journal of Personality and Social Psychology, 59, 1216-1229.

Goldberg, L. R. (1992). The development of markers of the big-five factor structure. Psychological Assessment, 4, 26-42.

Goldberg, L. R. (1999). A broad-bandwidth, public-domain, personality inventory measuring the lower-level facets of several five-factor models. In I. Mervielde, I. Deary, F. De Fruyt, \& F. Ostendorf (Eds.), Personality Psychology in Europe (Vol. 7, pp. 7-28). Tilburg, The Netherlands: Tilburg University Press.

Gustafson, P. E. (1998). Gender differences in risk perception: Theoretical and methodological perspectives. Risk Analysis, 18, 805-811.

Hampson, S. E., Andrews, J. A., Barckley, M., Lichtenstein, E., \& Lee, M. E. (2000). Conscientiousness, perceived risk, and riskreduction behaviors: A preliminary study. Health Psychology, 19, 496-500.

Helmreich, R. L., Foushee, H. C., Benson, R., \& Russini, W. (1986). Cockpit resource management: Exploring the attitude-performance linkage. Aviation, Space, \& Environmental Medicine, 57, 1198-1200.

Hermand, D., Karsenty, S., Py, Y., Guillet, L., Chauvin, B., Simeone, A., Munoz Sastre, M. T., \& Mullet, E. (2003). Risk target: An interactive context factor in risk perception. Risk Analysis, 23, 821-828.

Hermand, D., Mullet, E., \& Rompteaux, L. (1999). Societal risk perception among children, adolescents, adults, and elderly people. Journal of Adult Development, 6, 137-143.

Hofstee, W. K. B., De Raad, B., \& Goldberg, L. R. (1992). Integration of the big five and circumplex approaches to trait structure. Journal of Personality and Social psychology, 63, 146-163.

Howard, P. J., \& Howard, J. M. (1995). An Introduction to the Five-Factor Model of Personality for Human Resources Professionals. Retrieved December, 2004, from Center for Applied Cognitive Studies (CentACS) (http:// www.centacs.com/quickstart.htm).

Källmén, H. (2000). Manifest anxiety, general self-efficacy and locus of control as determinants of personal and general risk perception. Journal of Risk Research, 3, 111-120.

Karpowicz-Lazreg, C., \& Mullet, E. (1993). Societal risks as seen by the French public. Risk Analysis, 13, 253-258.

Kouabenan, D. R. (1998). Beliefs and the perception of risks and accidents. Risk Analysis, 18, 243-252.

Lemos Giráldez, S., \& Fidalgo Aliste, A. M. (1997). Personality dispositions and health-related habits and attitudes: A crosssectional study. European Journal of Personality, 11, 197-209.

Macri, D., \& Mullet, E. (2003). Cross-cultural differences in risk perception: A typological approach. Unpublished manuscript.

Mardberg, B., Nienmaa, P., Hillström, B., \& Carlstedt, B. (1994). Myers-Briggs Type Indicator Manual. Stockholm: Psykologiförlaget.

Mullet, E., Duquesnoy, C., Raiff, P., Fahrasmane, R., \& Namur, E. (1993). The evaluative factor of risk perception. Journal of Applied Social Psychology, 23, 1594-1605.

Mullet, E., Lazreg, C., Candela, C., \& Neto, F. (2005). The Scandinavian way of perceiving societal risks. Journal of Risk Research, 8, 19-30.

Palmer, C. G. S. (2003). Risk perception: Another look at the "white male" effect. Health, Risk \& Society, 5, 71-83.

Paunonen, S. V., \& Ashton, M. C. (2001). Big five factors and facets and the prediction of behavior. Journal of Personality and Social Psychology, 81, 524-539. 
Pilisuk, M., \& Acredolo, C. (1988). Fear of technological hazards: One concern or many? Social Behaviour, 3, 17-24.

Rogers, G. O. (1997). The dynamics of risk perception: How does perceived risk respond to risk events? Risk Analysis, 17, 745757.

Saucier, G., \& Goldberg, L. R. (1996). The language of personality: Lexical perspectives of the five-factor model. In J. S. Wiggings (Ed.), The Five-Factor Model of Personality: Theoretical Perspectives (pp. 21-50). New York: Guilford

Saucier, G., \& Goldberg, L. R. (2002). Assessing the big five: Applications of 10 psychometric criteria to the development of marker scales. In B. De Raad \& M. Perugini (Eds.), Big Five Assessment (pp. 29-58). Göttingen, Germany: Hogrefe and Huber Publishers.

Saucier, G., \& Ostendorf, F. (1999). Hierarchical subcomponents of the big-five personality factors: A cross-language replication. Journal of Personality and Social Psychology, 76, 613-627.

Siegrist, M., Cvetkovitch, G., \& Roth, C. (2000). Salient value similarity, social trust, and risk/benefit perception. Risk Analysis, $20,353-362$

Sjöberg, L. (2000). Factors in risk perception. Risk Analysis, 20, $1-11$.

Sjöberg, L. (2003). Distal factors in risk perception. Journal of Risk Research, 6, 187-211.

Sjöberg, L., \& af Wahlberg, A. (2002). Risk perception and new ages beliefs. Risk Analysis, 22, 751-764.
Slovic, P. (1987). Perception of risk. Science, 236, 280-285.

Slovic, P., Fischhoff, B., \& Lichtenstein, S. (1979). Rating the risks. Environment, 21, 14-20; 36-39.

Slovic, P., Fischhoff, B. \& Lichtenstein, S. (1980). Facts and fears: Understanding perceived risks. In R. C. Schwing \& W. A. Alberts, Jr. (Eds.), Societal Risk Assessment: How Safe Is Safe Enough? (pp. 181-214). New York: Plenum Press.

Slovic, P., Fischhoff, B., \& Lichtenstein, S. (1985). Characterizing perceived risk. In R. Kates, C. Hohenemser, \& J. X. Kasperson (Eds.), Perilous Progress: Managing the Hazards of Technology (pp. 91-125). Boulder, CO: Westview Press.

Spielberger, C. D., Gorsuch, R. L., \& Lushene, R. E. (1970). Manual for the State-Trait Anxiety Inventory. Palo Alto, CA: Consulting Psychologist Press.

Viklund, M. (2003). Trust and risk perception in Western Europe: A cross-national study. Risk Analysis, 23, 727738.

Vollrath, M., Knoch, D., \& Cassano, L. (1999). Personality, risky health behaviour, and perceived susceptibility to health risks. European Journal of Personality, 13, 39-50.

Vollrath, M., \& Torgersen, S. (2002). Who takes health risks? A probe into eight personality types. Personality and Individual Differences, 32, 1185-1197.

Wildavsky, A., \& Dake, K. (1990). Theories of risk perception: Who fears what and why. Daedalus, 112, 41-50. 
